\title{
Hirschsprung disease-type D brachydactyly syndrome
}

INSERM

\section{Source}

INSERM. (1999). Orphanet: an online rare disease and orphan drug data base.

Hirschsprung disease-type D brachydactyly syndrome. ORPHA:2150

Hirschsprung disease-type D brachydactyly syndrome is characterized by Hirschsprung disease and absence or hypoplasia of the nails and distal phalanges of the thumbs and great toes (type $D$ brachydactyly). It has been described in four males from one family (two brothers and two maternal uncles). Transmission appears to be $\mathrm{X}$-linked recessive but autosomal dominant inheritance with incomplete penetrance in females can not be ruled out. 